\title{
Evaluation of a Completion Total Mesorectal Excision in Patients After Local Excision of Rectal Cancer: A Word of Caution
}

\author{
Julia T. van Groningen, MD ${ }^{\mathrm{a}, \mathrm{b}}$; Pieter van Hagen, $\mathrm{MD}$, $\mathrm{PhD}$; ; Rob A.E.M. Tollenaar, MD, $\mathrm{PhD}^{\mathrm{a}}$; \\ Jurriaan B. Tuynman, MD, $\mathrm{PhD}^{\mathrm{d}}$; Perla J. Marang-van de Mheen, $\mathrm{PhD}^{\mathrm{e}}$; Pascal G. Doornebosch, MD, $\mathrm{PhD}^{\mathrm{c}}$; \\ Pieter J. Tanis, MD, PhD; ; and Eelco J.R. de Graaf, MD, $\mathrm{PhD}^{c}$; on behalf of the Dutch Colorectal Audit
}

\section{Abstract}

Background: According to Dutch guidelines, locally excised, low-risk, pT1 or ypT0-1 rectal cancer should not necessarily be followed by completion total mesorectal excision (CTME) in contrast to rectal cancers with higher T stages or unfavorable features. This study evaluated CTME after local excision at a national level with possible determinants for decision-making. Methods: All patients in the Dutch Colorectal Audit (DCRA) who underwent local excision of rectal cancer between 2012 and 2015 were included. Guideline adherence for performing CTME was determined with univariate and multivariate analyses to identify factors related to noncompliance. Results: According to the guidelines, of 530 included patients, cTME was indicated in 283 (53\%), and among those, was performed in 82 (29\%). Guideline adherence for performing CTME improved significantly $(P<.001)$, from $10 \%$ in 2012 to $44 \%$ in 2015 . Lower Charlson comorbidity index in patients with high-risk pT1 rectal cancer and younger patients (aged 61-70 years vs $\geq 80$ years) with pT $\geq 2$ rectal cancer were associated with increased performance of CTME (odds ratio [OR], 13.50; $95 \% \mathrm{Cl}, 1.39-131.32$, and OR, 6.25; 95\% Cl, 1.83-21.31, respectively). Conclusions: In this population-based study from the Netherlands, only a minority of patients underwent CTME after local excision of rectal cancer with pathologic features indicating the need for further treatment according to the guidelines. Although the percentage of patients undergoing cTME increased over time, the study indicated a tendency toward rectal-preserving treatment with potential oncologic risks.

\section{Background}

Total mesorectal excision (TME) is the gold standard for curative treatment of non-locally advanced rectal cancer. Together with preoperative radiotherapy (RT), TME as a standardized surgical technique has significantly improved local control of rectal cancer over the past decades. The disadvantages of TME include a high rate of postoperative morbidity, risk of mortality, and re-

\footnotetext{
aDepartment of Surgery, Leiden University Medical Center, Leiden; ${ }^{b}$ Dutch Institute for Clinical Auditing, Leiden; 'Department of Surgery, IJsselland Hospital, Capelle a/d IJssel; 'Department of Surgery, VU University Medical Center, Amsterdam; 'Department of Medical Decision Making, Leiden University Medical Center, Leiden; and fDepartment of Surgery, Academic Medical Center, Amsterdam, the Netherlands.

Submitted June 11, 2017; accepted for publication March 14, 2018.

The authors have disclosed that they have no financial interests, arrangements, affiliations, or commercial interests with the manufacturers of any products discussed in this article or their competitors.
}

duced quality of life (QoL). ${ }^{1-4}$ Rectal-preserving surgery can be performed as an alternative in selected patients, thereby reducing postoperative morbidity and mortality and improving QoL. ${ }^{5,6}$ Introduction of nationwide screening programs and the use of both neoadjuvant chemoradiation and radiotherapy have led to an increase in patients eligible for rectal-preserving surgery with curative intent. ${ }^{?}$

Author contributions: Study concept and design: van Groningen, van Hagen, Doornebosch, Tanis, de Graaf. Data acquisition: Dutch Colorectal Audit. Quality control of data and algorithms: van Groningen, van Hagen. Data analysis and interpretation: van Groningen, van Hagen, Doornebosch, Tanis, de Graaf. Statistical analysis: van Groningen, Marang-van Mheen. Manuscript preparation: van Groningen, van Hagen. Manuscript editing: van Groningen, van Hagen, Doornebosch, Tanis, de Graaf, Marang-van Mheen. Critical revision: All authors.

Correspondence: Julia T. van Groningen, MD, Dutch Institute for Clinical Auditing, Rijnsburgerweg 10, 2333 ZA, Leiden, the Netherlands.

Email: j.vangroningen@dica.nl 
Local excision only is considered an alternative to TME for early-stage, low-risk rectal cancer, defined as pT1,cN0,M0, with favorable histopathology (diameter $<3 \mathrm{~cm}$, good to moderate differentiation, no lymphovascular invasion [LVI], and negative resection margins), because recurrence rates of locally excised low-risk T1 rectal cancers have been reported to be $<5 \%$, and morbidity, mortality, and hospital stay are significantly lower compared with TME. ${ }^{8,9}$ If the pathology of the local excision specimen shows a high-risk $\mathrm{T} 1$ rectal cancer or if the tumor is $\geq \mathrm{T} 2$, the patient will have unacceptable, high recurrence rates $(>15 \%)$ and possibly reduced survival without further treatment compared with both cTME and TME. ${ }^{10}$ To enable rectal-preserving treatment in these higher risk early-stage rectal cancers, neoadjuvant therapy followed by local excision in patients with (near) complete response (ypT0-1) was recently introduced. ${ }^{11-13}$ Similarly, more advanced rectal cancers with a routine indication for neoadjuvant RT and a favorable response have been approached with local excision of the residual lesion or even a "watch-and-wait" strategy. ${ }^{14}$ In patients who experience a moderate to no response to neoadjuvant therapy (ypT2 or more invasive), recurrence rates are high and cTME is advised..$^{15}$ For early-stage rectal cancers that have already been locally excised, adjuvant chemoRT has been suggested as an alternative, but lacks conclusive evidence. ${ }^{16}$ Long-term outcomes of both neoadjuvant and adjuvant therapy and local excision need to be confirmed by large prospective randomized trials. Currently, the Dutch national guidelines consider these treatments experimental and state that these should only be offered within a trial setting. cTME is advised in stages higher than ypT0-1 if treatment is intentionally curative. ${ }^{17}$

Since 2009, the Dutch Colorectal Audit (DCRA), formerly known as the Dutch Surgical Colorectal Audit (DSCA), a nationwide qualityimprovement project, has prospectively collected patient and tumor characteristics, diagnostics, treatments, and outcomes of all patients undergoing colorectal cancer (CRC) surgery. The DCRA has been useful in monitoring trends and making recommendations considering treatment protocols. ${ }^{18}$ Since 2012, details on rectal-preserving surgery have been registered.

This study evaluated guideline adherence to cTME after local excision of rectal cancer in the Netherlands and its development over time, and investigated possible determinants for performing cTME.

\section{Methods}

Data

Data from the DCRA were used. All Dutch hospitals performing CRC resections have to participate. Internal and external verification of the database was performed. In 2011, >94\% of patients who underwent surgical treatment of CRC were registered in the DCRA (then DSCA). Further details of this data set regarding methodology have been described in previous publications. ${ }^{19}$

\section{Patients}

No ethical approval or informed consent was required for this study under Dutch law. All patients who underwent local excision of primary rectal cancer between January 2012 and December 2015 and were registered in the DCRA were evaluated $(\mathrm{N}=691)$. Patients were eligible for analysis if information on tumor location, date of surgery, and 30-day mortality was available. Patients with an unknown pathologic T stage $(n=77)$ or pT0 stage who did not receive neoadjuvant therapy $(n=34)$ were excluded because the indication for cTME could not be determined. Patients with a positive clinical nodal stage $(n=49)$ and those with distant metastases $(n=1)$ were also excluded. A total of 530 patients were deemed eligible and these were allocated to 5 groups based on either yp T stage or pT stage (dependant on whether the patient received neoadjuvant therapy), histopathologic characteristics, and neoadjuvant treatment (Figure 1).

\section{Definitions}

Local excision was defined as any surgical local excision including transanal open surgery, transanal endoscopic microsurgery (TEM), or transanal minimally invasive surgery (TAMIS). Low-risk pT1 rectal cancer was defined in the Dutch guidelines as (having a) diameter $<3 \mathrm{~cm}$, good to moderate differentiation, no LVI, and negative resection margins $(>1 \mathrm{~mm})$. Patients with pT1 disease and positive $(\leq 1 \mathrm{~mm})$ or unknown resection margins, poor or unknown differentiation, and/or known LVI were considered to have high-risk pT1 rectal cancer. In the DCRA, tumor diameter was not registered, and consequently was not 
van Groningen et al

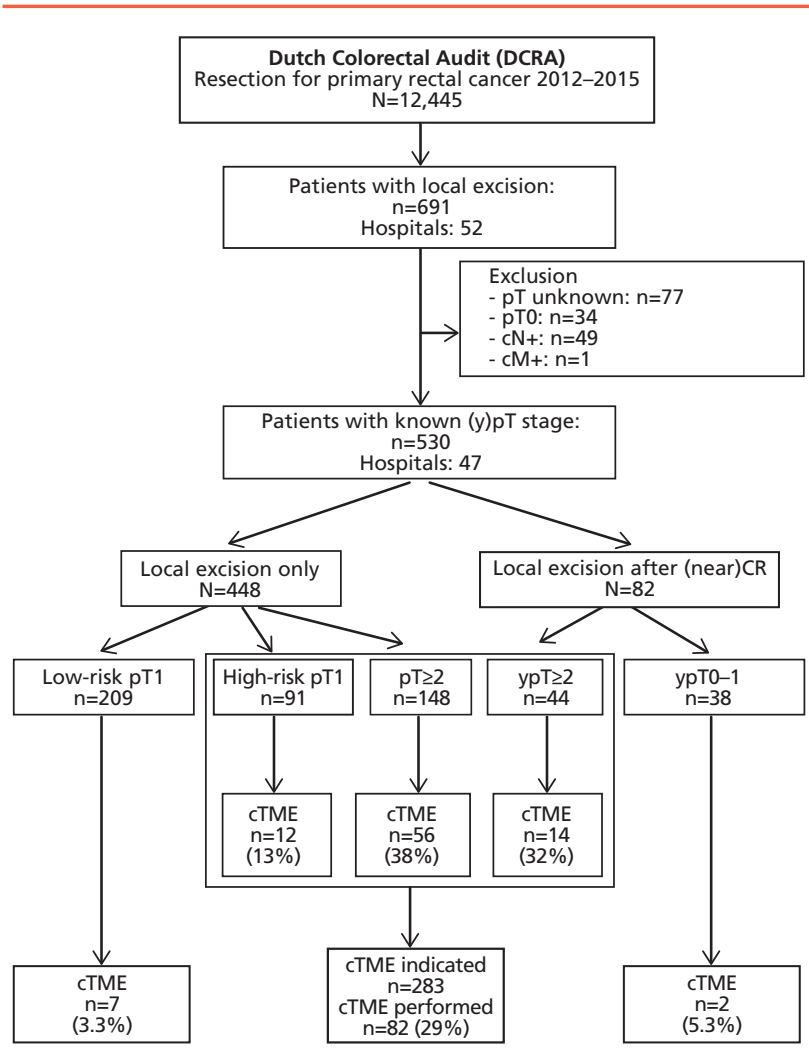

Figure 1. Patient eligibility.

Abbreviations: near(CR), near complete response; CTME, complete total mesorectal excision.

taken into account when classifying tumors as low or high risk. Information on LVI was only available for patients who underwent cTME. Absence of margin and/or differentiation scores was also considered a high-risk criterion, but absence of information on LVI was not a high-risk criterion on its own.

\section{Statistical Analysis}

The number of patients treated with local excision only and local excision with cTME in each histopathologic group was determined for each year. The significance of the time trend of cTME was analyzed using the chi-square for trend test.

To determine guideline adherence in a group of patients that was likely to be eligible for cTME, the proportion of cTME was calculated for patients with an indication for both cTME and TME and an American Society of Anesthesiologists (ASA) score of 1 to 2, a normal body mass index (BMI; 20-25 $\mathrm{kg} / \mathrm{m}^{2}$ ), and an age $<70$ years. Potential determinants for receiving cTME that were available in the DCRA data set were sex, age, BMI, Charlson comor- bidity index (CCI), ASA score, and tumor-associated complications. Patients receiving cTME were compared with those not receiving cTME in the high-risk $\mathrm{p} T 1$ or $\mathrm{pT} \geq 2$ group, and the yp $\mathrm{T} \geq 2$ group based on these potential determinants for clinical decision-making. Only variables that showed significance $(P<.05)$ in univariate analysis were included in a multivariate logistic regression model; $P<.05$ was considered statistically significant and $P<.1$ was considered as a trend to significance. Statistical analyses were performed using SPSS Statistics, version 22 (SPSS Inc.).

\section{Results}

A total of 530 patients from 50 hospitals were included in this study. Figure 1 shows the inclusion and exclusion criteria and the number of patients in the 5 different groups based on predefined histopathologic characteristics: low-risk pT1, high-risk pT1, $\mathrm{pT} \geq 2$, ypT $\geq 2$, and ypT0-1. Table 1 specifies the division between low-risk and high-risk pT1.

Local excision without neoadjuvant therapy was performed in 448 patients, of whom 47\% $(n=209)$ had low-risk pT1 rectal cancer. Of the remaining 239 patients, $148(62 \%)$ had $\geq \mathrm{pT} 2$ rectal cancer. Of the 91 patients with high-risk pT1 (38\%), 15 (17\%) had positive or unknown resection margins after local excision, $77(85 \%)$ had a poor or unknown differentiation grade, and 2 (2\%) had known LVI

\begin{tabular}{|c|c|c|}
\hline & $\mathbf{n}$ & $\%$ \\
\hline Low risk & 209 & 100 \\
\hline $\begin{array}{l}\text { Negative margins, good to moderate } \\
\text { differentiation, no LVI }\end{array}$ & 7 & 3.3 \\
\hline $\begin{array}{l}\text { Negative margins, good to moderate } \\
\text { differentiation, LVI unknown }\end{array}$ & 202 & 96.7 \\
\hline High risk & 91 & 100 \\
\hline $\begin{array}{l}\text { Positive margins, good differentiation, } \\
\text { LVI unknown }\end{array}$ & 9 & 9.9 \\
\hline $\begin{array}{l}\text { Positive margins, differentiation unknown, } \\
\text { LVI unknown }\end{array}$ & 2 & 2.2 \\
\hline $\begin{array}{l}\text { Negative margins, differentiation poor, } \\
\text { LVI unknown }\end{array}$ & 4 & 4.4 \\
\hline $\begin{array}{l}\text { Negative margins, differentiation unknown, } \\
\text { LVI unknown }\end{array}$ & 70 & 76.9 \\
\hline $\begin{array}{l}\text { Negative margins, good/moderate differentiation, } \\
\text { LVI present }\end{array}$ & 2 & 2.2 \\
\hline $\begin{array}{l}\text { Margins unknown, differentiation unknown, } \\
\text { LVI unknown }\end{array}$ & 1 & 1.1 \\
\hline $\begin{array}{l}\text { Margins unknown, good differentiation, } \\
\text { LVI unknown }\end{array}$ & 3 & 3.3 \\
\hline
\end{tabular}


(Table 1). Local excision after neoadjuvant therapy was performed in 82 patients, of whom $47 \%(n=38)$ had a (near) pathologic complete response (yp T0-1). Neoadjuvant therapy consisted of short-course RT with delayed surgery in 34 patients $(41 \%)$, chemoRT in $40(49 \%)$, chemotherapy only in $1(1 \%)$, and other neoadjuvant therapy in $7(9 \%)$. Patient and tumor characteristics of the 5 histopathologic groups are summarized in Table 2.

According to the guidelines, cTME was indicated in 53\% $(n=283)$ of all patients based on histopathologic characteristics (Figure 1), but was performed in only $29 \%$ of these patients (82/283). The proportion of cTME was $13 \%$ in patients with high-risk pT1 rectal cancer, $38 \%$ in patients with $\mathrm{pT} \geq 2$ disease, and $32 \%$ in patients with ypT $\geq 2$ after neoadjuvant therapy. Figure 2 shows the number of patients who received local excision only and local excision with cTME in each histopathologic category in each year. The percentage of patients with an indication for cTME (high-risk pT1, pT $\geq 2$, or ypT2) who also underwent cTME increased significantly $(P<.001)$, from $10 \%$ in 2012 to $44 \%$ in 2015 . In patients aged $<70$ years with a normal BMI and
ASA score of 1 to 2 , guideline adherence to cTME was 36\% (23/64). Table 3 shows that, compared with their counterparts who did not undergo cTME, patients with high-risk pT1 who underwent cTME had lower CCI, those with $\mathrm{pT} \geq 2$ who underwent cTME were younger and had lower ASA scores, and those with ypT $\geq 2$ who underwent cTME had lower ASA scores.

The multivariate analysis (Table 4) revealed that in patients with high-risk pT1, a lower CCI was an independent determinant for performing cTME, with an odds ratio (OR) of 13.50 (95\% CI, 1.39131.32 ) for patients with a CCI of 1 versus $\geq 2$. For patients with $\mathrm{pT} \geq 2$, lower age was an independent determinant for performing cTME (OR, 6.25; 95\% CI, $1.83-21.31$ for age $61-70$ vs $\geq 81$ years, and OR, 3.24 ; $95 \%$ CI, $0.96-10.95$ for age $71-80$ vs $\geq 81$ years [trend toward significance]).

\section{Discussion}

More than $50 \%$ of all patients who underwent a local excision of rectal cancer had an indication for cTME according to the national guidelines. Sur-

\begin{tabular}{|c|c|c|c|c|c|c|}
\hline \multicolumn{7}{|c|}{$\begin{array}{c}\text { Pathologic Stage } \\
\text { n (\%) }\end{array}$} \\
\hline & T1, Low-Risk & T1, High-Risk & $\mathrm{pT} \geq 2$ & ypT $\geq 2$ & урт0/1 & Total \\
\hline \multicolumn{7}{|l|}{ Sex } \\
\hline Male & $135(64.4)$ & $53(58.2)$ & $89(60.1)$ & $26(59.1)$ & $23(60.5)$ & $326(62)$ \\
\hline Female & $74(35.6)$ & 38 (41.8) & 59 (39.9) & $18(40.9)$ & 15 (39.5) & $204(38)$ \\
\hline \multicolumn{7}{|l|}{$\mathrm{BMI}, \mathrm{kg} / \mathrm{m}^{2}$} \\
\hline Missing & $3(1.4)$ & $2(2.1)$ & 0 & 0 & 0 & $5(1)$ \\
\hline$<25$ & $77(36.8)$ & $28(30.8)$ & $67(45.3)$ & $21(47.7)$ & $8(21.1)$ & $201(38)$ \\
\hline $25-30$ & $90(43.1)$ & $44(48.4)$ & $65(43.9)$ & $14(31.8)$ & $23(60.5)$ & $236(45)$ \\
\hline$>30$ & $39(18.7)$ & $17(18.7)$ & $16(10.8)$ & $9(20.5)$ & $7(18.4)$ & $88(17)$ \\
\hline \multicolumn{7}{|l|}{ Age, y } \\
\hline$\leq 60$ & 38 (18.2) & $16(17.6)$ & $23(15.5)$ & $9(20.5)$ & $5(13.2)$ & $91(17)$ \\
\hline $61-70$ & $80(38.3)$ & 39 (42.9) & $47(31.8)$ & $14(31.8)$ & $16(42.1)$ & $196(37)$ \\
\hline $71-80$ & $74(35.4)$ & $33(36.3)$ & $50(33.8)$ & $9(20.5)$ & $13(34.2)$ & $179(34)$ \\
\hline$\geq 81$ & $17(8.1)$ & $3(3.3)$ & $28(18.9)$ & $12(27.3)$ & $4(10.5)$ & $64(12)$ \\
\hline \multicolumn{7}{|l|}{$\mathrm{CCl}$} \\
\hline 0 & $103(49.3)$ & $58(63.7)$ & $74(50.0)$ & $19(43.2)$ & $23(60.5)$ & $277(52)$ \\
\hline 1 & $55(26.3)$ & $14(15.4)$ & 32 (21.6) & $10(22.7)$ & $5(13.2)$ & $116(22)$ \\
\hline$\geq 2$ & $51(24.4)$ & $19(20.9)$ & $42(28.4)$ & $15(34.1)$ & $10(26.3)$ & $137(26)$ \\
\hline \multicolumn{7}{|l|}{ ASA score } \\
\hline $1-2$ & $174(83.3)$ & 85 (93.4) & $110(74.3)$ & $28(63.6)$ & 31 (81.6) & $428(81)$ \\
\hline $3-5$ & $35(16.8)$ & $6(6.6)$ & $38(25.7)$ & $16(36.4)$ & $7(18.4)$ & $102(19)$ \\
\hline \multicolumn{7}{|c|}{ Pathologic T stage } \\
\hline pT0/pT1 & $209(100)$ & $91(100)$ & 0 & 0 & $38(100)$ & $338(64)$ \\
\hline pT2 & 0 & 0 & $121(81.8)$ & $35(79.5)$ & 0 & $156(29)$ \\
\hline рT3-4 & 0 & 0 & $27(18.2)$ & $9(20.5)$ & 0 & $36(7)$ \\
\hline
\end{tabular}

Abbreviations: ASA, American Society of Anesthesiologists; BMI, body mass index; $\mathrm{CCl}$, Charlson comorbidity index. 
van Groningen et al

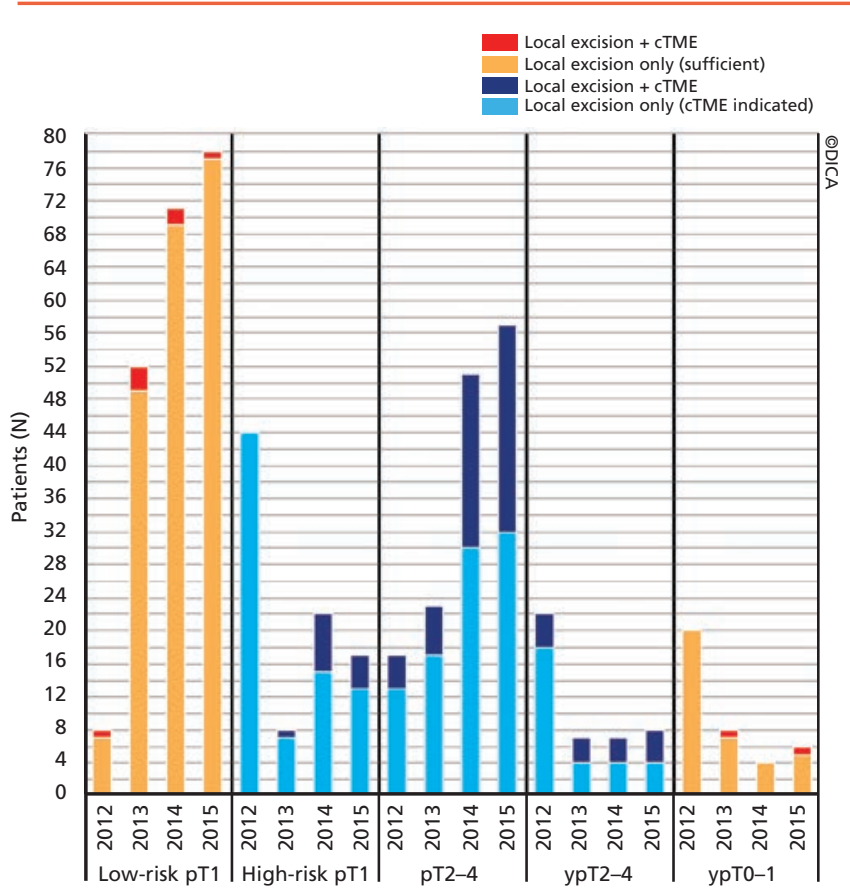

Figure 2. Number of patients with local excision of rectal cancer, with or without completion total mesorectal excision (CTME) per histopathologic group per year. prisingly, this cTME was performed in only 29\% of these patients. Even considering only $\mathrm{pT} \geq 2$ stage after local excision, $62 \%$ of patients did not undergo cTME. This nonadherence to the guidelines with a significant oncologic risk for patients could not be explained by patient characteristics. Lower CCI in the patients with high-risk pT1 disease and younger age in patients with $\mathrm{pT} \geq 2$ disease appeared to be independent determinants for performing cTME. However, the effects are small, and in the group with an indication for cTME who were relatively healthy, most patients still seem to be undertreated, leaving them with a significant risk of local recurrence.

This is the first study to address this specific question. A treatment proposal for a patient with rectal cancer is multifactorial and depends on patient characteristics and patient choice. Next to good oncologic outcome, sustaining QoL is increasingly becoming a primary goal of treatment. However, guidelines still focus on effectively controlling the disease. ${ }^{3,20}$ Although Schiphorst et al ${ }^{20}$ showed that guideline adherence for patients with rectal cancer

\begin{tabular}{|c|c|c|c|c|c|c|c|c|c|}
\hline & \multicolumn{3}{|c|}{ High-Risk pT1 } & \multicolumn{3}{|c|}{$\mathrm{pT} \geq 2$} & \multicolumn{3}{|c|}{ ypT $\geq 2$} \\
\hline & $\begin{array}{c}\text { Local } \\
\text { Excision Only } \\
n(\%)\end{array}$ & $\begin{array}{l}\text { Local Excision } \\
\text { With cTME } \\
\text { n (\%) }\end{array}$ & $\begin{array}{c}X^{2} \\
P \text { Value }\end{array}$ & $\begin{array}{c}\text { Local } \\
\text { Excision Only } \\
n(\%)\end{array}$ & $\begin{array}{l}\text { Local Excision } \\
\text { With cTME } \\
\text { n (\%) }\end{array}$ & $\begin{array}{c}\mathrm{X}^{2} \\
P \text { Value }\end{array}$ & $\begin{array}{c}\text { Local } \\
\text { Excision Only } \\
n(\%)\end{array}$ & $\begin{array}{c}\text { Local Excision } \\
\text { With cTME } \\
\text { n (\%) }\end{array}$ & $\begin{array}{c}\mathrm{X}^{2} \\
P \text { Value }\end{array}$ \\
\hline Sex & & & .206 & & & .647 & & & .402 \\
\hline Male & $44(83.0)$ & $9(17.0)$ & & $54(60.7)$ & 35 (39.3) & & $19(73.1)$ & $7(26.9)$ & \\
\hline Female & $35(92.1)$ & $3(7.9)$ & & $38(64.4)$ & $21(35.6)$ & & $11(61.1)$ & 7 (38.9) & \\
\hline BMI, $\mathrm{kg} / \mathrm{m}^{2}$ & & & .120 & & & .528 & & & \\
\hline Missing & $2(100)$ & 0 & & & & & & & $.035^{\mathrm{a}}$ \\
\hline$<25$ & 27 (96.4) & $1(3.6)$ & & $41(61.2)$ & $26(38.8)$ & & $11(52.4)$ & $10(47.6)$ & \\
\hline $25-30$ & $35(79.5)$ & $9(20.5)$ & & $39(60.0)$ & $26(40.0)$ & & $10(71.4)$ & $4(28.6)$ & \\
\hline$>30$ & $15(88.2)$ & $2(11.8)$ & & $12(75.0)$ & $4(25.0)$ & & $9(100)$ & 0 & \\
\hline Age, y & & & .731 & & & $.004^{a}$ & & & .252 \\
\hline$\leq 60$ & $13(81.3)$ & $3(18.8)$ & & $16(69.6)$ & $7(30.4)$ & & $4(44.4)$ & $5(55.6)$ & \\
\hline $61-70$ & 35 (89.7) & $4(10.3)$ & & $21(44.7)$ & $26(55.3)$ & & $9(64.3)$ & $5(35.7)$ & \\
\hline $71-80$ & $28(84.8)$ & $5(15.2)$ & & $31(62.0)$ & $19(38.0)$ & & $7(77.8)$ & $2(22.2)$ & \\
\hline$\geq 81$ & $3(100)$ & 0 & & $24(85.7)$ & $4(14.3)$ & & $10(83.3)$ & $2(16.7)$ & \\
\hline $\mathrm{CCl}$ & & & $.002^{\mathrm{a}}$ & & & .209 & & & .811 \\
\hline 0 & $53(91.4)$ & $5(8.6)$ & & $41(55.4)$ & $33(44.6)$ & & $12(63.2)$ & $7(36.8)$ & \\
\hline 1 & $8(57.1)$ & $6(42.9)$ & & $21(65.6)$ & $11(34.4)$ & & $7(70.0)$ & $3(30.0)$ & \\
\hline$\geq 2$ & $18(94.7)$ & $1(5.3)$ & & $30(71.4)$ & $12(28.6)$ & & $11(73.3)$ & $4(26.7)$ & \\
\hline ASA score & & & .131 & & & $.037^{a}$ & & & $.006^{a}$ \\
\hline $1-2$ & $75(88.2)$ & $10(11.8)$ & & $63(57.3)$ & $47(42.7)$ & & $15(53.6)$ & $13(46.4)$ & \\
\hline $3-5$ & $4(66.7)$ & $2(33.3)$ & & $29(76.3)$ & $9(23.7)$ & & $15(93.8)$ & $1(6.3)$ & \\
\hline Pathologic & age & & $.000^{\mathrm{a}}$ & & & $.000^{\mathrm{a}}$ & & & .362 \\
\hline pT0-1 & $79(86.8)$ & $12(13.2)$ & & 0 & 0 & & 0 & 0 & \\
\hline pT2 & 0 & 0 & & $84(69.4)$ & $37(30.6)$ & & $25(71.4)$ & $10(28.6)$ & \\
\hline рT3-4 & 0 & 0 & & $8(29.6)$ & $19(70.4)$ & & $5(55.6)$ & $4(44.4)$ & \\
\hline
\end{tabular}

Abbreviations: ASA, American Society of Anesthesiologists; BMI, body mass index; CCl, Charlson comorbidity index; cTME, completion total mesorectal excision. asignificant difference. 
Evaluation of cTME After Local Excision

\begin{tabular}{|c|c|c|c|}
\hline & $\begin{array}{l}\text { High-Risk pT1 } \\
\qquad(\mathrm{n}=91)\end{array}$ & $\begin{array}{c}\mathrm{pT} \geq 2 \\
(\mathrm{n}=148)\end{array}$ & $\begin{array}{l}\mathrm{ypT} \geq 2 \\
(\mathrm{n}=44)\end{array}$ \\
\hline & OR $(95 \% \mathrm{Cl})$ & OR $(95 \% \mathrm{Cl})$ & OR $(95 \% \mathrm{Cl})$ \\
\hline \multicolumn{4}{|c|}{$\mathrm{BMI}, \mathrm{kg} / \mathrm{m}^{2}$} \\
\hline$<25$ & & & $1.76(0.39-8.05)$ \\
\hline $25-30$ & & & 1 \\
\hline \multicolumn{4}{|l|}{$>30$} \\
\hline \multicolumn{4}{|l|}{ Age, y } \\
\hline$\leq 60$ & & $2.13(0.52-8.74)$ & \\
\hline $61-70$ & & $6.25(1.83-21.31)^{\mathrm{a}}$ & \\
\hline $71-80$ & & $3.24(0.96-10.95)^{b}$ & \\
\hline$\geq 81$ & & 1 & \\
\hline \multicolumn{4}{|l|}{$\mathrm{CCl}$} \\
\hline 0 & $1.70(0.19-15.52)$ & & \\
\hline 1 & $13.50(1.39-131.32)^{\mathrm{a}}$ & & \\
\hline$\geq 2$ & 1 & & \\
\hline \multicolumn{4}{|l|}{ ASA score } \\
\hline $1-2$ & & $1.89(0.78-4.61)$ & $5.66(0.59-54.14)$ \\
\hline $3-5$ & & 1 & 1 \\
\hline
\end{tabular}

Abbreviations: ASA, American Society of Anesthesiologists; BMI, body mass index $\mathrm{CCl}$, Charlson comorbidity index; OR, odds ratio.

asignificant $P<.05$.

bTrend to significance $P<.1$.

overall declines significantly with increasing age, our study shows only some association between age and performance of cTME after neoadjuvant therapy. When discussing treatment options with an individual patient after local excision, shared decisionmaking may lead to refraining from cTME. Several factors may contribute to this: first, patient's choice, because some older studies show that cTME after local excision is associated with high colostomy rates, and still has a substantial risk of local recurrence. ${ }^{21}$ Although the technique of TME has improved, these risks may influence the patient's choice, even after precise counseling on possible negative side effects. Furthermore, patients could choose to decline cTME because some studies show promising results in disease-free survival after neoadjuvant therapy and local excision of T2 rectal cancer in very select patients. ${ }^{12,13}$ It may also be a doctor's preference not to perform cTME, perhaps based on underestimation of the possible risks of the rectal-preserving treatment strategy. Either way, improving preoperative staging could possibly lower the number of patients in whom local excision is performed when TME is indicated. This generates an additional challenge, because information on relevant parameters such as LVI and submucosal infiltration in biopsies is marginal. Patients should be informed before first treatment that the local excision can be curative, but could also turn out to be a diagnostic procedure that should be followed by cTME in the case of unfavorable histology. This could help change patients' and doctors' preferential treatment.

The study has some limitations. First, the DCRA is a self-reported database by surgeons; therefore, the risk of under-registration exists. In some patients who have undergone cTME, this might not be sufficiently registered. Still, the DCRA is a large obligatory nationwide database, and under-registration might only explain some of the discrepancy. Furthermore, the data set was not built specifically for this study, but to activate an audit cycle in CRC care-which is why, for example, important information on diameter of the tumor was not available. Results of this study caused the DCRA to improve their database and work on improving standardized reporting of pathology after local excision. The discussion on highrisk criteria in pT1 rectal cancer is ongoing. Several studies have addressed this issue, but definite conclusions are hard to draw. Therefore, although national guidelines have implemented high-risk criteria, whether all assumed high-risk pT1 rectal cancers have had an indication for cTME is questionable. In this study, information on high-risk criteria was lacking in a large portion of patients, which makes the allocation to low- or high-risk insecure. However, even after exclusion of all pT1 cancers, the analyses show similar results. Lastly, although nonadherence could have been patient choice, information on this is lacking.

Despite these limitations, this study has some implications for the future. First, although clinical understaging might be an explanation for the large number of patients who needed cTME, this study suggests a discrepancy in clinical and pathologic staging of early-stage rectal cancer. If there was no discrepancy between clinical and pathologic staging of early-stage rectal cancers, cTME would not be needed, because all patients would receive the appropriate treatment directly. This finding suggests the need for quality improvement in radiologic staging of rectal cancer, such as by MRI or endorectal ultrasound. Additionally, the lack of information on high-risk criteria indicates the need for quality improvement of the clinical audit database, but possibly also among pathology practices or techniques evaluating these criteria. This becomes especially important given the expanding population of patients with early-stage rectal cancer and the increas- 
van Groningen et al

ing interest in rectal-preserving surgery. Preoperative staging by a specialized multidisciplinary team is of the utmost importance for selecting patients suitable for a local excision. For some patients, nonadherence to a guideline could very well be the best choice. However, it is very important to reveal and explain the recurrence risks to patients in a way that allows them to form a well-informed decision. Lastly, for an optimal balance between treatment-related morbidity and oncologic control, another focus of research is needed: searching for alternatives to cTME. In the Netherlands, a large, multicentered, randomized trial is underway to compare oncologic safety of adjuvant chemoRT versus cTME. ${ }^{22}$ In our study, ad- juvant therapy was only given to 6 patients who did not receive CTME when it was indicated (data not shown), and therefore the start of this trial did not influence our study.

\section{Conclusions}

A large group of patients seems to receive insufficient treatment of rectal cancer, leading to possible compromised oncologic outcomes. This inadequacy cannot be explained only by frailty of the patients. These results expose a need for quality improvement in preoperative staging and additional treatment after local excision of rectal cancer in the Netherlands.

\section{References}

1. Kapiteijn E, Putter H, van de Velde CJ. Impact of the introduction and training of total mesorectal excision on recurrence and survival in rectal cancer in The Netherlands. Br J Surg 2002;89:1142-1149.

2. Peeters KC, Marijnen CA, Nagtegaal ID, et al. The TME trial after a median follow-up of 6 years. Ann Surg 2007;246:693-701.

3. Rutten HJ, den Dulk M, Lemmens VE, et al. Controversies of total mesorectal excision for rectal cancer in elderly patients. Lancet Oncol 2008;9:494-501.

4. Peeters KC, van de Velde CJ, Leer JW, et al. Late side effects of shortcourse preoperative radiotherapy combined with total mesorectal excision for rectal cancer: increased bowel dysfunction in irradiated patients-a Dutch Colorectal Cancer Group study. J Clin Oncol 2005;23:6199-6206.

5. Verseveld M, Barendse RM, Gosselink MP, et al. Transanal minimally invasive surgery: impact on quality of life and functional outcome. Surg Endosc 2016;30:1184-1187.

6. Allaix ME, Rebecchi F, Giaccone C, et al. Long-term functional results and quality of life after transanal endoscopic microsurgery. Br J Surg 2011;98:1635-1643.

7. Gross CP, Andersen MS, Krumholz HM, et al. Relation between Medicare screening reimbursement and stage at diagnosis for older patients with colon cancer. JAMA 2006;296:2815-2822.

8. Lutz MP, Zalcberg JR, Glynne-Jones R, et al. Second St. Gallen European Organisation for Research and Treatment of Cancer Gastrointestinal Cancer Conference: consensus recommendations on controversial issues in the primary treatment of rectal cancer. Eur J Cancer 2016;63:11-24.

9. Allaix ME, Arezzo A, Morino M. Transanal endoscopic microsurgery for rectal cancer: T1 and beyond? An evidence-based review. Surg Endosc 2016;30:4841-4852.

10. Borschitz T, Gockel I, Kiesslich R, Junginger T. Oncological outcome after local excision of rectal carcinomas. Ann Surg Oncol 2008;15:3101-3108.

11. Verseveld M, de Graaf EJ, Verhoef C, et al. Chemoradiation therapy for rectal cancer in the distal rectum followed by organ-sparing transanal endoscopic microsurgery (CARTS study). Br J Surg 2015;102:853-860.

12. Garcia-Aguilar J, Renfro LA, Chow OS, et al. Organ preservation for clinical T2NO distal rectal cancer using neoadjuvant chemoradiotherapy and local excision (ACOSOG Z6041): results of an open-label, single-arm, multi-institutional, phase 2 trial. Lancet Oncol 2015;16:1537-1546.

13. Stipa F, Picchio M, Burza A, et al. Long-term outcome of local excision after preoperative chemoradiation for ypT0 rectal cancer. Dis Colon Rectum 2014;57:1245-1252.

14. Rana N, Chakravarthy AB, Kachnic LA. Neoadjuvant treatment for locally advanced rectal cancer: new concepts in clinical trial design. Curr Treat Options Oncol 2017;18:13.

15. Lezoche E, Baldarelli M, Lezoche $G$, et al. Randomized clinical trial of endoluminal locoregional resection versus laparoscopic total mesorectal excision for T2 rectal cancer after neoadjuvant therapy. Br J Surg 2012;99:1211-1218.

16. Borstlap WA, Coeymans TJ, Tanis PJ, et al. Meta-analysis of oncological outcomes after local excision of pT1-2 rectal cancer requiring adjuvant (chemo)radiotherapy or completion surgery. Br J Surg 2016;103:11051116.

17. Dutch guideline for colorectal cancer. Available at: http://www.oncoline. $\mathrm{nl} /$ coloretaalcarcinoom. Accessed June 11, 2017.

18. van Leersum NJ, Snijders HS, Wouters MW, et al. Evaluating national practice of preoperative radiotherapy for rectal cancer based on clinical auditing. Eur J Surg Oncol 2013;39:1000-1006.

19. Van Leersum NJ, Snijders HS, Henneman D, et al. The Dutch surgical colorectal audit. Eur J Surg Oncol 2013;39:1063-1070.

20. Schiphorst AH, Verweij NM, Pronk A, Hamaker ME. Age-related guideline adherence and outcome in low rectal cancer. Dis Colon Rectum 2014;57:967-975.

21. van Gijn W, Brehm V, de Graaf E, et al. Unexpected rectal cancer after TEM: outcome of completion surgery compared with primary TME. Eur J Surg Oncol 2013;39:1225-1229.

22. Borstlap WA, Tanis PJ, Koedam TW, et al. A multi-centred randomised trial of radical surgery versus adjuvant chemoradiotherapy after local excision for early rectal cancer. BMC Cancer 2016;16:513. 